\title{
Diabetes mellitus, glycated haemoglobin and C-peptide levels in relation to pancreatic cancer risk: a study within the European Prospective Investigation into Cancer and Nutrition (EPIC) cohort
}

\author{
V. A. Grote • S. Rohrmann • A. Nieters • L. Dossus • A. Tjønneland • J. Halkjær • \\ K. Overvad • G. Fagherazzi - M. C. Boutron-Ruault • S. Morois • B. Teucher • \\ S. Becker • D. Sluik • H. Boeing • A. Trichopoulou • P. Lagiou • D. Trichopoulos • \\ D. Palli $\cdot$ V. Pala $\cdot$ R. Tumino $\cdot$ P. Vineis $\cdot$ S. Panico $\cdot$ L. Rodríguez $\cdot$ E. J. Duell $\cdot$ \\ E. Molina-Montes • M. Dorronsoro • J. M. Huerta $~$ E. Ardanaz $~$ S. M. Jeurnink • \\ J. W. J. Beulens • P. H. M. Peeters • M. Sund • W. Ye • B. Lindkvist • D. Johansen • \\ K. T. Khaw $\cdot$ N. Wareham $\cdot$ N. Allen $\cdot$ F. Crowe $\cdot$ M. Jenab $\cdot$ I. Romieu $\cdot$ \\ D. S. Michaud $\cdot$ E. Riboli $\cdot$ D. Romaguera $\cdot$ H. B. Bueno-de-Mesquita $\cdot$ R. Kaaks
}

Received: 1 June 2011 /Accepted: 31 August 2011 /Published online: 28 September 2011

(C) Springer-Verlag 2011

\begin{abstract}
Aims/hypothesis There has been long-standing debate about whether diabetes is a causal risk factor for pancreatic cancer or a consequence of tumour development. Prospective epidemiological studies have shown variable relationships between pancreatic cancer risk and blood markers of
\end{abstract}

V. A. Grote $\cdot$ S. Rohrmann · A. Nieters $\cdot$ L. Dossus $\cdot$ B. Teucher $\cdot$

S. Becker $\cdot$ R. Kaaks $(\bowtie)$

Division of Cancer Epidemiology c020,

German Cancer Research Center (DKFZ),

Im Neuenheimer Feld 581,

69120 Heidelberg, Germany

e-mail: r.kaaks@dkfz.de

\section{S. Rohrmann}

Division of Cancer Epidemiology and Prevention, Institute of Social and Preventive Medicine,

Zurich, Switzerland

\section{A. Nieters}

Center of Chronic Immunodeficiency, University Medical Center, Freiburg, Germany

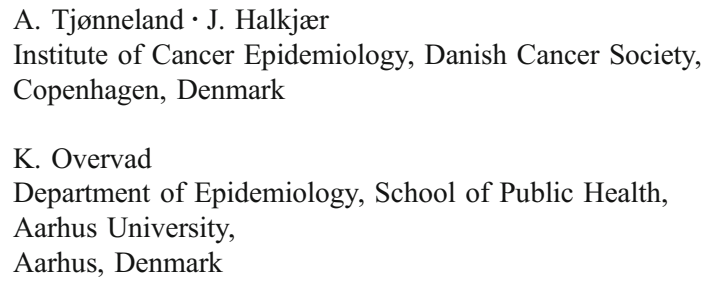

glucose and insulin metabolism, overall and as a function of lag times between marker measurements (blood donation) and date of tumour diagnosis.

Methods Pre-diagnostic levels of $\mathrm{HbA}_{1 \mathrm{c}}$ and C-peptide were measured for 466 participants with pancreatic cancer and 466 individually matched controls within the European

G. Fagherazzi • M. C. Boutron-Ruault · S. Morois Inserm, Centre for Research in Epidemiology and Population Health,

Villejuif, France

G. Fagherazzi $\cdot$ M. C. Boutron-Ruault $\cdot$ S. Morois

Paris South University,

Villejuif, France

S. Becker

Institute of Laboratory Medicine,

Clinical Chemistry and Molecular Diagnostics,

University Hospital Leipzig,

Leipzig, Germany

D. Sluik $\cdot$ H. Boeing

Department of Epidemiology,

German Institute of Human Nutrition Potsdam-Rehbruecke,

Nuthetal, Germany

A. Trichopoulou $\cdot$ P. Lagiou

WHO Collaborating Center for Food and Nutrition Policies, Department of Hygiene, Epidemiology and Medical Statistics, University of Athens Medical School,

Athens, Greece 
Prospective Investigation into Cancer and Nutrition. Conditional logistic regression models were used to estimate ORs for pancreatic cancer.

Results Pancreatic cancer risk gradually increased with increasing pre-diagnostic $\mathrm{HbA}_{1 \mathrm{c}}$ levels up to an OR of $2.42(95 \%$ CI $1.33,4.39$ highest $[\geq 6.5 \%, 48 \mathrm{mmol} / \mathrm{mol}]$ vs lowest $[\leq 5.4 \%, 36 \mathrm{mmol} / \mathrm{mol}]$ category), even for individuals with $\mathrm{HbA}_{1 \mathrm{c}}$ levels within the non-diabetic range. Cpeptide levels showed no significant relationship with pancreatic cancer risk, irrespective of fasting status. Analyses showed no clear trends towards increasing hyperglycaemia (as marked by $\mathrm{HbA}_{1 \mathrm{c}}$ levels) or reduced pancreatic beta cell responsiveness (as marked by Cpeptide levels) with decreasing time intervals from blood donation to cancer diagnosis.

Conclusions/interpretation Our data on $\mathrm{HbA}_{1 \mathrm{c}}$ show that individuals who develop exocrine pancreatic cancer tend to have moderate increases in $\mathrm{HbA}_{1 \mathrm{c}}$ levels, relatively independently of obesity and insulin resistance - the classic and major risk factors for type 2 diabetes. While there is no strong difference by lag time, more data are needed on this in order to reach a firm conclusion.

Keywords C-peptide $\cdot \mathrm{HbA}_{1 \mathrm{c}} \cdot$ Cohort study $\cdot$ Diabetes . EPIC $\cdot$ Pancreatic cancer

\section{Abbreviation \\ EPIC European Prospective Investigation into Cancer and Nutrition}

\footnotetext{
A. Trichopoulou

Hellenic Health Foundation,

Athens, Greece

P. Lagiou $\cdot$ D. Trichopoulos

Department of Epidemiology, Harvard School of Public Health,

Boston, MA, USA

P. Lagiou $\cdot$ D. Trichopoulos

Bureau of Epidemiologic Research, Academy of Athens,

Athens, Greece

D. Palli

Molecular and Nutritional Epidemiology Unit,

Cancer Research and Prevention Institute - ISPO,

Florence, Italy

V. Pala

Nutritional Epidemiology Unit, Fondazione IRCCS Istituto

Nazionale Tumori,

Milano, Italy

R. Tumino

Cancer Registry and Histopathology Unit,

'Civile-M. P. Arezzo' Hospital,

Ragusa, Italy

\section{Introduction}

Well-established lifestyle and environmental risk factors for exocrine pancreatic cancer include smoking [1,2], chronic and acute forms of pancreatitis [3], and excess body weight [4], although the last is a rather weak risk factor for pancreatic cancer in comparison with several other cancer types [5].

A further, well-documented risk factor for pancreatic cancer is long-standing diabetes, although many studies have also documented the occurrence of diabetes relatively shortly before diagnosis of a pancreatic tumour. This adds fuel to the debate on whether diabetes is a possible cause or, more likely, a consequence of tumour development $[6,7]$. In relation to the first theory, it has been speculated that elevated plasma glucose levels and/or increased pancreatic insulin secretion, which are both intrinsic to the development of type 2 diabetes, could serve as possible mechanisms explaining the risk association between diabetes and pancreatic tumour development (e.g. by stimulating cellular growth and by inhibiting apoptosis $[8,9])$. According to the second theory, diabetes would occur primarily as a result of a developing tumour, which progressively may entrap or invade pancreatic beta cell islets [10], thus causing a gradual destruction of functional beta cell capacity [11], reductions in insulin secretion capacity, and progressive hyperglycaemia.

To further elucidate the possible cause-and/or-effect relationships between diabetes mellitus and pancreatic

P. Vineis

HuGeF Foundation,

Torino, Italy

P. Vineis

MRC/HPA Centre for Environment and Health, School of Public

Health, Imperial College London,

London, UK

S. Panico

Department of Clinical and Experimental Medicine,

Federico II University,

Naples, Italy

L. Rodríguez

Public Health and Participation Directorate, Health and Health

Care Services Council,

Asturias, Spain

\section{E. J. Duell}

Unit of Nutrition, Environment and Cancer, Cancer Epidemiology

Research Program, Catalan Institute of Oncology

(ICO-IDIBELL), L'Hospitalet de Llobregat,

Barcelona, Spain 
cancer, it is important to further elucidate the temporal relationship between pancreatic cancer occurrence and preexisting disturbances of glucose and insulin metabolism. Previous prospective studies have shown statistically significant associations of pre-diagnostic glucose [12-15] and insulin levels $[15,16]$ with pancreatic cancer risk; however, results were inconsistent when lag time was taken into consideration.

Here, we report results from a nested case-control study within the European Prospective Investigation into Cancer and Nutrition (EPIC), measuring pre-diagnostic serum levels of $\mathrm{HbA}_{1 \mathrm{c}}$ and $\mathrm{C}$-peptide in healthy individuals at enrolment, to calculate risk estimates for the association of those markers with pancreatic cancer. To examine the complex, possibly time-dependent relationship of glucose, insulin, diabetes and pancreatic cancer, we additionally stratified our analyses by lag time between study enrolment (with blood donation) and pancreatic cancer diagnosis.

\section{Methods}

Study population The design and methods of the EPIC study have been described by Haftenberger et al. and Riboli et al. $[17,18]$. Briefly, 519,978 men and women, mostly aged

E. J. Duell $\cdot$ E. Molina-Montes $\cdot$ M. Dorronsoro · J. M. Huerta

E. Ardanaz

CIBER Epidemiología y Salud Pública (CIBERESP)

URL: www.ciberesp.es

E. Molina-Montes

Andalusian School of Public Health,

Granada, Spain

\section{Dorronsoro}

Public Health Division of Gipuzkoa, Investigation Institute IIS

Biodonostia, Health Department Basque Country,

Gipuzkoa, Spain

\section{J. M. Huerta}

Department of Epidemiology,

Murcia Regional Health Authority,

Murcia, Spain

\section{E. Ardanaz}

Navarre Public Health Institute,

Pamplona, Spain

S. M. Jeurnink · H. B. Bueno-de-Mesquita

Department of Gastroenterology and Hepatology, University

Medical Centre Utrecht (UMCU),

Utrecht, the Netherlands

J. W. J. Beulens $\cdot$ P. H. M. Peeters

Julius Center, University Medical Center Utrecht,

Utrecht, the Netherlands between 35 and 70 years, were recruited by 23 collaborating centres in ten European countries (Denmark, France, Germany, Greece, Italy, the Netherlands, Norway, Spain, Sweden and the UK) between 1992 and 2000. Ethical review boards of the International Agency for Research on Cancer (IARC) and local institutions gave approval for the study and all participants provided informed consent.

Blood sample collection and storage In seven EPIC countries (France, Germany, Greece, Italy, the Netherlands, Spain and the UK) serum, plasma, erythrocytes and DNA were aliquoted and stored in liquid nitrogen $\left(-196^{\circ} \mathrm{C}\right)$ in a central biorepository. In Denmark, blood samples were stored locally in nitrogen vapour $\left(-150^{\circ} \mathrm{C}\right)$ and in Sweden in freezers at $-70^{\circ} \mathrm{C}$. For the present study, Norway was excluded because blood samples had only recently been collected and very few pancreatic cancer cases had been diagnosed after blood donation.

Follow-up for cancer incidence and vital status Incident cancer cases were identified by population cancer registries (Denmark, Italy, the Netherlands, Spain, Sweden and the UK) or by a combination of methods including health insurance records, cancer and pathology registries and

J. W. J. Beulens $\cdot$ P. H. M. Peeters

Department of Epidemiology and Biostatistics, School of Public

Health, Faculty of Medicine, Imperial College London,

London, UK

M. Sund

Departments of Surgical and Perioperative Sciences/Surgery and Public Health and Clinical Medicine, Nutrition Research,

Umeå University,

Umeå, Sweden

W. Ye

Department of Medical Epidemiology and Biostatistics,

Karolinska Institute,

Stockholm, Sweden

W. Ye

The Medical Biobank, Umeå University,

Umeå, Sweden

B. Lindkvist

Institute of Medicine, Sahlgrenska Academy,

University of Gothenburg,

Gothenburg, Sweden

D. Johansen

Department of Surgery, Skåne University Hospital, SUS,

Malmö, Sweden

K. T. Khaw

Department of Public Health and Primary Care,

University of Cambridge,

Cambridge, UK 
active follow-up of study participants (France, Germany, Greece). In all EPIC centres, data on vital status are collected through mortality registries, in combination with health insurance data (France) or active follow-up (Greece). For the present project on pancreatic cancer, the study period was defined as the latest date of complete follow-up for both cancer incidence and vital status in each EPIC centre, and varied from December 2002 to December 2006. For Germany, Greece, and France, the end of follow-up was considered to be the last known contact, the date of diagnosis or the date of death, whichever came first.

Selection of case and control participants Pancreatic cancer incidence data were coded according to ICD-10 (www.who.int/classifications/icd/en/) and included all invasive exocrine pancreatic cancers that were coded as C25 (25.0-25.3, 25.7-25.9). Exclusion criteria were the occurrence of other malignant tumours preceding the diagnosis of pancreatic cancer, except for non-melanoma skin cancer, and the non-availability of blood specimens. By the end of December 2006, 638 incident cases of pancreatic cancer were identified, of which 578 were primary exocrine pancreatic tumours. For 466 of these cases blood specimens were available. Of these, 342 (76\%) were microscopically confirmed. For the remaining $24 \%$ diagnosis was confirmed by clinical symptoms, imaging results and/or physical examination. For each case, one control participant, alive and free of cancer at time of diagnosis of the index case, was selected using incidence density sampling. Matching

\section{N. Wareham \\ MRC Epidemiology Unit, \\ Cambridge, UK}

N. Allen $\cdot$ F. Crowe

Cancer Epidemiology Unit Nuffield, Department of Clinical

Medicine, University of Oxford,

Oxford, UK

M. Jenab · I. Romieu

International Agency for Research on Cancer (IARC-WHO), Lyon, France

D. S. Michaud $\cdot$ E. Riboli $\cdot$ D. Romaguera

School of Public Health, Imperial College London,

London, UK

D. S. Michaud

Division of Biology and Medicine, Brown University,

Providence, RI, USA

H. B. Bueno-de-Mesquita

Centre for Nutrition and Health (CVG), National Institute for

Public Health and the Environment (RIVM),

Bilthoven, the Netherlands characteristics were study centre, sex, age at enrolment ( \pm 6 months), date at entry in the cohort, time between blood sampling and time of last consumption of food and drink $(<3,3-6, \geq 6 \mathrm{~h})$.

Laboratory assays Serum or EDTA plasma samples (Swedish centres) from cases and individually matched controls from one centre were analysed within the same analytical batch. $\mathrm{HbA}_{1 \mathrm{c}}$ was measured in erythrocyte haemolysate with the BioRad Variant Haemoglobin Analyzer at the Karolinska University Laboratory (Karolinska University Hospital, Stockholm, Sweden). Units are expressed as percentages of haemoglobin and in $\mathrm{mmol} /$ mol. C-peptide was analysed by double-antibody radioimmunoassay using the RIA DSL-7000 kit (Diagnostic Systems Laboratories, Webster, TX, USA) at the German Cancer Research Centre, Division of Cancer Epidemiology (Heidelberg, Germany). Units of C-peptide are expressed as $\mathrm{ng} / \mathrm{ml}$. Mean intra-batch and inter-batch coefficients of variations were $2.5 \%$ and $4.4 \%$ for $\mathrm{HbA}_{1 \mathrm{c}}$, and $8.3 \%$ and $19 \%$ for C-peptide.

Statistical analyses Differences between cases and controls were tested by paired $t$ tests for continuous variables and by $\chi^{2}$ tests for categorical variables.

Conditional logistic regression was used to calculate ORs and the corresponding 95\% CIs for the associations between $\mathrm{HbA}_{1 \mathrm{c}}$ and $\mathrm{C}$-peptide and pancreatic cancer risk; $\mathrm{HbA}_{1 \mathrm{c}}$ and C-peptide were computed on a continuous scale and as categorised variables. Continuous measurements of C-peptide were log-transformed to approximate normality, whereas transformation of $\mathrm{HbA}_{1 \mathrm{c}}$ levels had no effect on normality and ORs, and therefore non-transformed $\mathrm{HbA}_{1 \mathrm{c}}$ values were used in all statistical procedures. Category cutpoints were based on the distribution among controls and $p$ values for trends across categories were based on the median value within each quartile. To assess the association of pancreatic cancer risk among individuals at the highest risk for progression to diabetes $\left(\mathrm{HbA}_{1 \mathrm{c}} \geq 6.0[42 \mathrm{mmol} / \mathrm{mol}]\right.$ and $<6.5 \%$ [48 mmol $/ \mathrm{mol}]$ ) and among those having diabetes $\left(\mathrm{HbA}_{1 \mathrm{c}} \geq 6.5 \%\right.$ [48 $\left.\left.\mathrm{mmol} / \mathrm{mol}\right]\right)$ [19], the highest $\mathrm{HbA}_{1 \mathrm{c}}$ category was further divided into these two groups. ORs were also computed to assess the association of diabetes with pancreatic cancer risk. In general, participants were defined as having diabetes if they self-reported the condition at recruitment and/or had $\mathrm{HbA}_{1 \mathrm{c}}$ levels $\geq 6.5 \%$ (48 $\left.\mathrm{mmol} / \mathrm{mol}\right)$ at baseline $(n=95)$.

Conditional logistic regression was also used to assess the association of possible confounders with pancreatic cancer risk other than those controlled for by matching; these include BMI (continuous), waist circumference (continuous), WHR (continuous), alcohol intake at 
recruitment (continuous), physical activity (active, moderately active, moderately inactive, inactive), smoking status (never, former, current, missing), and diabetes at recruitment (yes, no, missing). Variables remained in the model if they were associated with pancreatic cancer, correlated with $\mathrm{HbA}_{1 \mathrm{c}}$ or $\mathrm{C}$-peptide, or changed the logistic $\beta$ estimate by more than $10 \%$. We finally adjusted for BMI as a continuous variable and for smoking status as a categorical variable (never smoker; former smoker who stopped less than 10 years ago; former smokers who stopped 10 or more years ago; current smokers with $1-9$, $10-19$, or $\geq 20$ cigarettes per day; smoking status unknown). To explore other possible confounding effects, we additionally adjusted for $\mathrm{C}$-peptide or $\mathrm{HbA}_{1 \mathrm{c}}$ in further models.

In addition, analyses were stratified by factors that could modify the relationship between $\mathrm{HbA}_{1 \mathrm{c}}$ or C-peptide levels and pancreatic cancer. Tests for statistical heterogeneity between subgroups were calculated by adding crossproduct terms in the logistic regression models over quartiles of $\mathrm{HbA}_{1 \mathrm{c}}$ and C-peptide and testing the significance with the Wald test, adjusted for confounders.

All statistical analyses were conducted using the Statistical Analysis System (SAS) software package, Version 9.2 (SAS Institute, Cary, NC, USA).

\section{Results}

Baseline characteristics of the study population are shown in Table 1. Mean follow-up time for cases was 5.3 years (range $0-13$ years). Of those with pancreatic cancer, $32 \%$ were current smokers compared with $22 \%$ of controls, whereas never smokers were more common among controls than among cases. At baseline recruitment, diabetes, either self-reported or defined by elevated $\mathrm{HbA}_{1 \mathrm{c}}$ level, was more frequent among those who developed pancreatic cancer.

Among women, those with incident pancreatic cancer had significantly higher BMI and waist circumference than their matched controls but no significant differences in BMI or waist circumference were seen among men (Table 1). Stratifying by smoking and diabetes status, significant case-control differences in BMI and waist circumference appeared to be restricted to never-smoking diabetes patients. Case-control differences in $\mathrm{HbA}_{1 \mathrm{c}}$ were greatest among former smokers, and particularly among former smokers who were also diabetic at baseline $\left(\operatorname{mean}_{\text {cases }}=\right.$ $8.1 \%$ [65 mmol $/ \mathrm{mol}]$, mean $_{\text {controls }}=6.6 \%$ [49 $\left.\mathrm{mmol} / \mathrm{mol}\right], p$ difference $=0.002)$. C-peptide concentrations were significantly higher among non-fasting (geometric mean $=6.59 \mathrm{ng} /$ $\mathrm{ml}[95 \% \mathrm{CI} 6.10,7.13])$ compared with fasting participants $(3.35 \mathrm{ng} / \mathrm{ml}[95 \%$ CI 3.04, 3.70]), and among diabetes patients $(6.83 \mathrm{ng} / \mathrm{ml}$ [95\% CI 5.64, 8.27]) compared with non-diabetes patients $(5.07 \mathrm{ng} / \mathrm{ml}[95 \%$ CI $4.79,5.36])$. In addition, former smokers $(6.24 \mathrm{ng} / \mathrm{ml}$ [95\% CI 5.74, 6.78]) had higher C-peptide levels than current $(5.13 \mathrm{ng} / \mathrm{ml}[95 \%$ CI $4.62,5.69])$ and never smokers $(4.59 \mathrm{ng} / \mathrm{ml}[95 \% \mathrm{CI}$ $4.21,5.02])$.

Association of diabetes with cancer risk Conditional logistic regression analyses showed a clear increase in pancreatic cancer risk overall among diabetic participants at recruitment (OR 1.74 [95\% CI 1.12, 2.71]). This association was particularly strong among individuals with a follow-up time of 2 years or less (OR 3.41 [95\% CI 1.26, 9.20]), compared with those with a longer follow-up time (OR 1.45 [95\% CI 0.89, 2.37]), although heterogeneity was not significant $(p=0.227)$.

Associations of $\mathrm{HbA}_{1 c}$ with cancer risk Increasing $\mathrm{HbA}_{1 \mathrm{c}}$ percentages were associated with a statistically significant increase in pancreatic cancer risk up to an OR of 2.60 comparing highest vs lowest category (Table 2). Multivariate adjustment for BMI or waist circumference, and smoking status as well as C-peptide levels only slightly attenuated this risk association.

Analyses by lag time between the date of blood donation (biomarker measurements) and date of pancreatic cancer diagnosis showed no statistically significant heterogeneity of the association of $\mathrm{HbA}_{1 \mathrm{c}}$ with pancreatic cancer risk, although the association was somewhat stronger for participants with follow-up times longer than the median length of follow-up of 5.2 years than for those with shorter follow-up times (Table 2). Also, within less than 2 years of follow-up the association between $\mathrm{HbA}_{1 \mathrm{c}}$ concentration and pancreatic cancer risk was of similar strength (adjusted OR 1.39 [95\% CI 0.48, 4.03]) to that seen for longer follow-up times (adjusted OR 1.57 [95\% CI 0.97, 2.54]; $p$ heterogeneity $=0.038$ ).

Although trend tests over categories of $\mathrm{HbA}_{1 \mathrm{c}}$ did not show a statistically significant heterogeneity by smoking status, stratification by smoking status did reveal a clearly stronger increase in pancreatic cancer risk with increasing $\mathrm{HbA}_{1 \mathrm{c}}$ concentration for never smokers, a somewhat weaker increase in risk among ex-smokers, and no increase in risk with increasing $\mathrm{HbA}_{1 \mathrm{c}}$ among current smokers (Table 2).

Associations of C-peptide with cancer risk Overall, Cpeptide concentrations showed no significant relationship with pancreatic cancer risk (Table 3). Multivariate adjustments for BMI or waist circumference, smoking categories, 
Table 1 Baseline characteristics of pancreatic cancer cases and matched control individuals
Mean $\mathrm{HbA}_{1 \mathrm{c}}$ values correspond to $42.2 \mathrm{mmol} / \mathrm{mol}$ for cases and $39.9 \mathrm{mmol} / \mathrm{mol}$ for controls

${ }^{\mathrm{a}}$ Values for continuous variables were based on paired $t$ tests; $p$ values for categorical variables were based on $\chi^{2}$ tests

${ }^{\mathrm{b}} \mathrm{C}$-peptide levels were reported as geometric means, as the distribution of the variable was not normal

\begin{tabular}{|c|c|c|c|}
\hline Variable & $\begin{array}{l}\text { Cases } \\
(n=466)\end{array}$ & $\begin{array}{l}\text { Controls } \\
(n=466)\end{array}$ & $p$ value $^{\mathrm{a}}$ \\
\hline Men, women (n) & 225,241 & 225,241 & \\
\hline Age at recruitment (years), mean (range) & $58(30-76)$ & $58(30-76)$ & Matched \\
\hline Age at diagnosis (years), mean (range) & $63(37-82)$ & - & \\
\hline Follow-up (years), mean (range) & $5.3(0-13)$ & - & \\
\hline Smoking status, n (\%) & & & 0.005 \\
\hline Never & $165(35)$ & $201(43)$ & \\
\hline Former & $147(32)$ & $158(34)$ & \\
\hline Current & $149(32)$ & $102(22)$ & \\
\hline Unknown & $5(1)$ & $5(1)$ & \\
\hline \multicolumn{4}{|l|}{ Alcohol intake at recruitment (g/day), mean $\pm \mathrm{SD}$} \\
\hline Men & $21 \pm 26$ & $23 \pm 30$ & 0.486 \\
\hline Women & $9 \pm 13$ & $8 \pm 11$ & 0.168 \\
\hline Fasting status, n (\%) & & & Matched \\
\hline Fasting $(\geq 6 \mathrm{~h})$ & $118(25)$ & $113(24)$ & \\
\hline In between $(3-6 \mathrm{~h})$ & $78(17)$ & $78(17)$ & \\
\hline Non-fasting $(<3 \mathrm{~h})$ & $184(40)$ & $190(41)$ & \\
\hline Unknown & $86(18)$ & $85(18)$ & \\
\hline \multicolumn{4}{|l|}{ Diabetes status, n (\%) } \\
\hline Self-reported diabetes at recruitment & $33(7)$ & $20(4)$ & 0.065 \\
\hline $\mathrm{HbA}_{1 \mathrm{c}} \geq 6.5 \%(48 \mathrm{mmol} / \mathrm{mol})$ & $53(12)$ & $30(7)$ & 0.008 \\
\hline $\begin{array}{l}\text { Self-reported diabetes or } \mathrm{HbA}_{1 \mathrm{c}} \geq 6.5 \% \\
(48 \mathrm{mmol} / \mathrm{mol})\end{array}$ & $59(13)$ & $36(8)$ & 0.012 \\
\hline Unknown & $19(4)$ & $18(4)$ & \\
\hline BMI $\left(\mathrm{kg} / \mathrm{m}^{2}\right)$, mean \pm SD & $26.6 \pm 4.3$ & $25.9 \pm 4.1$ & 0.007 \\
\hline Men & $26.8 \pm 3.6$ & $26.7 \pm 3.7$ & 0.690 \\
\hline Women & $26.4 \pm 5.0$ & $25.2 \pm 4.3$ & 0.002 \\
\hline Waist circumference $(\mathrm{cm})$, mean $\pm \mathrm{SD}$ & $90.1 \pm 12.8$ & $88.5 \pm 13.1$ & 0.030 \\
\hline Men & $96.4 \pm 9.9$ & $96.7 \pm 10.1$ & 0.788 \\
\hline Women & $84.2 \pm 12.5$ & $81.0 \pm 10.7$ & 0.001 \\
\hline WHR, mean \pm SD & $0.88 \pm 0.10$ & $0.88 \pm 0.10$ & 0.110 \\
\hline Men & $0.95 \pm 0.06$ & $0.95 \pm 0.06$ & 0.501 \\
\hline Women & $0.81 \pm 0.07$ & $0.81 \pm 0.06$ & 0.119 \\
\hline $\mathrm{HbA}_{1 \mathrm{c}}(\%)$, mean $\pm \mathrm{SD}$ & $6.01 \pm 1.1$ & $5.80 \pm 0.6$ & $<0.0001$ \\
\hline C-peptide $(\mathrm{ng} / \mathrm{ml})$, geometric mean $(95 \% \mathrm{CI})^{\mathrm{b}}$ & $5.46(5.08-5.86)$ & $5.05(4.67-5.47)$ & 0.161 \\
\hline
\end{tabular}

or $\mathrm{HbA}_{1 \mathrm{c}}$, or exclusion of diabetic individuals did not materially change these OR estimates. However, among those who had provided a blood sample under fasting conditions (last food consumption $\geq 6 \mathrm{~h}$ ago), increasing Cpeptide levels did show a tendency to increase risk of pancreatic cancer, although the risk was not statistically significant (Table 3).

OR estimates for increasing C-peptide levels did not vary by length of follow-up or smoking status (data not shown).

Further analyses stratified by sex, diabetes status, median BMI or waist circumference did not show statistically significant heterogeneity between these strata for risk associations with $\mathrm{HbA}_{1 \mathrm{c}}$ or C-peptide (data not shown).

\section{Discussion}

In this prospective study, we observed an increase in pancreatic cancer risk with increasing pre-diagnostic $\mathrm{HbA}_{1 \mathrm{c}}$ levels, even for participants with $\mathrm{HbA}_{1 \mathrm{c}}$ levels within the non-diabetic range. The association was only slightly weakened and remained statistically significant after adjustment for BMI or smoking status, and in stratified analyses was most apparent among never smokers. Contrary to $\mathrm{HbA}_{1 \mathrm{c}}$, pre-diagnostic levels of $\mathrm{C}$-peptide showed no significant associations with pancreatic cancer risk, irrespective of smoking or fasting status. Lag-time analyses showed no clear difference in the association of pancreatic cancer 
Table 2 ORs for pancreatic cancer $(95 \% \mathrm{CI})$ by category of $\mathrm{HbA}_{1 \mathrm{c}}$ overall and excluding diabetes patients, and stratified by median follow-up time, median BMI and smoking status

\begin{tabular}{|c|c|c|c|c|c|c|}
\hline \multirow[b]{2}{*}{ Quartile cut-offs (\%) } & \multicolumn{5}{|c|}{ Categories $^{\mathrm{a}}$} & \multirow[t]{2}{*}{$p$ value for trend $\mathrm{b}^{\mathrm{b}}$} \\
\hline & $\begin{array}{l}1 \\
4.8-5.4\end{array}$ & $\begin{array}{l}2 \\
5.5-5.7\end{array}$ & $\begin{array}{l}3 \\
5.8-5.9\end{array}$ & $\begin{array}{l}4 \\
6.0-6.4\end{array}$ & $\begin{array}{l}5 \\
6.5-11.0\end{array}$ & \\
\hline \multicolumn{7}{|l|}{ All participants ${ }^{\mathrm{c}}$} \\
\hline Number of cases/controls & $72 / 101$ & $131 / 151$ & $102 / 82$ & $97 / 91$ & $54 / 31$ & \\
\hline Crude & 1.0 & $1.24(0.83-1.85)$ & $1.75(1.14-2.67)$ & $1.59(1.03-2.45)$ & $2.60(1.49-4.56)$ & $<0.001$ \\
\hline Adjusted for smoking, BMI & 1.0 & $1.27(0.84-1.93)$ & $1.77(1.14-2.75)$ & $1.46(0.93-2.30)$ & $2.42(1.33-4.39)$ & 0.002 \\
\hline \multicolumn{7}{|l|}{ Excluding diabetic participants ${ }^{\mathrm{c}, \mathrm{d}}$} \\
\hline Number of cases/controls & $65 / 89$ & $122 / 134$ & $95 / 71$ & $83 / 71$ & - & \\
\hline Crude & 1.0 & $1.30(0.85-1.98)$ & $1.85(1.18-2.91)$ & $1.68(1.05-2.70)$ & & 0.010 \\
\hline Adjusted for smoking, BMI & 1.0 & $1.42(0.91-2.21)$ & $1.94(1.22-3.10)$ & $1.65(1.01-2.70)$ & & 0.020 \\
\hline \multicolumn{7}{|l|}{ Median follow-up time (5.2 years) ${ }^{\mathrm{c}}$} \\
\hline$<5.2$ years, number of cases/controls & $41 / 46$ & $54 / 75$ & $52 / 44$ & $83 / 63$ & - & \\
\hline Crude & 1.0 & $0.89(0.50-1.60)$ & $1.44(0.78-2.64)$ & $1.65(0.90-3.01)$ & & 0.069 \\
\hline Adjusted for smoking, BMI & 1.0 & $0.92(0.50-1.69)$ & $1.37(0.73-2.56)$ & $1.56(0.82-2.94)$ & & 0.187 \\
\hline$\geq 5.2$ years, number of cases/controls & $33 / 55$ & $77 / 77$ & $51 / 38$ & $68 / 59$ & - & \\
\hline Crude & 1.0 & $1.75(1.00-3.04)$ & $2.23(1.22-4.07)$ & $1.91(1.09-3.35)$ & & 0.050 \\
\hline Adjusted for smoking, BMI & 1.0 & $1.73(0.95-3.15)$ & $2.39(1.26-4.54)$ & $1.74(0.95-3.18)$ & & 0.061 \\
\hline \multicolumn{7}{|l|}{ Median BMI (men 26.7, women 24.6) } \\
\hline$<$ Median, number of cases/controls & $40 / 57$ & $65 / 79$ & $48 / 38$ & $51 / 53$ & - & \\
\hline Crude & 1.0 & $1.16(0.68-1.96)$ & $1.75(0.96-3.19)$ & $1.37(0.77-2.45)$ & & 0.150 \\
\hline Adjusted for smoking & 1.0 & $1.16(0.67-2.00)$ & $1.41(0.76-2.63)$ & $1.22(0.67-2.23)$ & & 0.442 \\
\hline$\geq$ Median, number of cases/controls & $34 / 44$ & $66 / 73$ & $55 / 44$ & $100 / 69$ & - & \\
\hline Crude & 1.0 & $1.25(0.71-2.21)$ & $1.73(0.94-3.18)$ & $2.07(1.18-3.62)$ & & 0.004 \\
\hline Adjusted for smoking & 1.0 & $1.27(0.72-2.27)$ & $1.81(0.98-3.36)$ & $1.92(1.08-3.41)$ & & 0.013 \\
\hline \multicolumn{7}{|l|}{ Smoking status ${ }^{\mathrm{e}}$} \\
\hline Never smoker, number of cases/controls & $25 / 54$ & $55 / 64$ & $37 / 35$ & $47 / 44$ & - & \\
\hline Crude & 1.0 & $1.84(1.01-3.37)$ & $2.36(1.20-4.64)$ & $2.41(1.26-4.60)$ & & 0.008 \\
\hline Adjusted for BMI & 1.0 & $1.76(0.96-3.23)$ & $2.20(1.11-4.34)$ & $2.15(1.11-4.17)$ & & 0.025 \\
\hline Former smoker, number of cases/controls & $19 / 30$ & $42 / 54$ & $32 / 25$ & $50 / 45$ & - & \\
\hline Crude & 1.0 & $1.20(0.58-2.49)$ & $1.97(0.88-4.42)$ & $1.73(0.83-3.60)$ & & 0.079 \\
\hline Adjusted for BMI & 1.0 & $1.19(0.58-2.46)$ & $1.93(0.86-4.35)$ & $1.65(0.78-3.49)$ & & 0.109 \\
\hline Current smoker, number of cases/controls & $29 / 16$ & $34 / 32$ & $33 / 22$ & $51 / 31$ & - & \\
\hline Crude & 1.0 & $0.60(0.27-1.35)$ & $0.85(0.37-1.97)$ & $0.92(0.42-2.04)$ & & 0.701 \\
\hline Adjusted for BMI & 1.0 & $0.61(0.27-1.36)$ & $0.85(0.37-1.97)$ & $0.89(0.40-1.97)$ & & 0.811 \\
\hline
\end{tabular}

$\mathrm{HbA}_{1 \mathrm{c}}$ category ranges $(\mathrm{Q})$ : Q1=28.9-35.5 mmol $/ \mathrm{mol}$; Q2=36.6-38.8 $\mathrm{mmol} / \mathrm{mol} ; \mathrm{Q} 3=39.9-41.0 \mathrm{mmol} / \mathrm{mol} ; \mathrm{Q} 4=42.1-46.4 \mathrm{mmol} / \mathrm{mol} ; \mathrm{Q} 5=$ $47.5-96.7 \mathrm{mmol} / \mathrm{mol}$

Uneven number of controls in $\mathrm{Hb}_{\mathrm{c}}$ categories because of accuracy of laboratory $\mathrm{HbA}_{1 \mathrm{c}}$ measurements. The laboratory assay measured $\mathrm{Hb} \mathrm{A}_{1 \mathrm{c}}$ to one decimal place and this resulted in nodes of participants with similar $\mathrm{HbA}_{1 \mathrm{c}}$ values. Therefore, it is not possible to equally distribute $\mathrm{HbA}_{1 \mathrm{c}}$ values of controls across the categories. The current distribution is based on a statistical method, which produces equal groups as accurately as possible. In subgroup analyses, $\mathrm{HbA}_{1 \mathrm{c}}$ categories 4 and 5 were collapsed into one category

${ }^{a}$ Category cut-points of $\mathrm{HbA}_{1 \mathrm{c}}$ were based on the distribution of controls

${ }^{\mathrm{b}} p$ trend test was based on median values of each category, adjusted for matching factors

${ }^{\mathrm{c}}$ Logistic regression conditioned on matching factors (EPIC recruitment centre, sex, age at recruitment, date at entry in the cohort, time between blood sampling and last consumption of foods and drinks). Adjusting variables in further model: smoking (never smoker; former smoker who stopped $<10$ years ago, $\geq 10$ years ago; current smokers with $1-9,10-19$, or $\geq 20$ cigarettes per day; smoking status unknown) and BMI (continuous)

${ }^{\mathrm{d}}$ Self-reported diabetes at recruitment and $/$ or $\mathrm{HbA}_{1 \mathrm{c}} \geq 6.5 \%(48 \mathrm{mmol} / \mathrm{mol})$

${ }^{\mathrm{e}}$ Unconditional logistic regression, adjusted for matching factors (EPIC recruitment centre, sex, age at recruitment, date at entry in the cohort, time between blood sampling and last consumption of foods and drinks). Adjusting variables in subgroup analysis by median BMI: smoking (never smoker; former smoker who stopped $<10$ years ago, $\geq 10$ years ago; current smokers with $1-9,10-19$ or $\geq 20$ cigarettes per day; smoking status unknown). Adjusting variables in subgroup analysis by smoking status: BMI (continuous)

$p$ interaction based on Wald test, crude $p$ interaction for median follow-up time $=0.320$, median $\mathrm{BMI}=0.627$, smoking status $=0.604$ 
Table 3 ORs for pancreatic cancer $(95 \%$ CI) by category of C-peptide overall, excluding diabetic participants, and by fasting status

\begin{tabular}{|c|c|c|c|c|c|}
\hline \multirow[b]{2}{*}{ Quartile cut-offs (ng/ml) } & \multicolumn{4}{|l|}{ Categories $^{\mathrm{a}}$} & \multirow[t]{2}{*}{$p$ value for trend $\mathrm{b}^{\mathrm{b}}$} \\
\hline & $\begin{array}{l}1 \\
0.08-2.95\end{array}$ & $\begin{array}{l}2 \\
2.99-5.46\end{array}$ & $\begin{array}{l}3 \\
5.48-9.26\end{array}$ & $\begin{array}{l}4 \\
9.27-19.82\end{array}$ & \\
\hline \multicolumn{6}{|l|}{ All participants } \\
\hline Number of cases/controls & $85 / 104$ & $114 / 105$ & $110 / 106$ & $111 / 105$ & \\
\hline Crude $^{c}$ & 1.0 & $1.42(0.93-2.16)$ & $1.38(0.89-2.13)$ & $1.42(0.90-2.23)$ & 0.299 \\
\hline Adjusted for smoking, BMI & 1.0 & $1.27(0.82-1.99)$ & $1.16(0.73-1.83)$ & $1.15(0.70-1.91)$ & 0.886 \\
\hline \multicolumn{6}{|l|}{ Excluding diabetic participants ${ }^{\mathrm{d}}$} \\
\hline Number of cases/controls & $78 / 85$ & $95 / 85$ & $86 / 91$ & $86 / 84$ & \\
\hline Crude $^{c}$ & 1.0 & $1.25(0.79-1.99)$ & $1.06(0.66-1.71)$ & $1.15(0.70-1.90)$ & 0.851 \\
\hline Adjusted for smoking, BMI & 1.0 & $1.23(0.76-1.99)$ & $1.00(0.61-1.65)$ & $1.09(0.64-1.87)$ & 0.957 \\
\hline \multicolumn{6}{|l|}{ By fasting status ${ }^{\mathrm{e}}$} \\
\hline Non-fasting, number of cases/controls & $18 / 24$ & $41 / 38$ & $46 / 51$ & $65 / 60$ & \\
\hline Crude $^{c}$ & 1.0 & $1.44(0.68-3.08)$ & $1.21(0.58-2.53)$ & $1.44(0.71-2.94)$ & 0.503 \\
\hline Adjusted for smoking, BMI & 1.0 & $1.45(0.67-3.13)$ & $1.16(0.54-2.47)$ & $1.29(0.62-2.70)$ & 0.807 \\
\hline In between, number of cases/controls & $18 / 19$ & $18 / 24$ & $19 / 15$ & $17 / 18$ & \\
\hline Crude $^{\mathrm{c}}$ & 1.0 & $0.80(0.32-1.96)$ & $1.33(0.52-3.39)$ & $0.99(0.39-2.54)$ & 0.770 \\
\hline Adjusted for smoking, BMI & 1.0 & $0.65(0.25-1.69)$ & $0.85(0.30-2.39)$ & $0.60(0.20-1.73)$ & 0.472 \\
\hline Fasting, number of cases/controls & $44 / 51$ & $40 / 34$ & $24 / 21$ & $9 / 5$ & \\
\hline Crude $^{c}$ & 1.0 & $1.39(0.75-2.60)$ & $1.38(0.65-2.90)$ & $2.20(0.65-7.38)$ & 0.186 \\
\hline Adjusted for smoking, BMI & 1.0 & $1.22(0.61-2.45)$ & $1.22(0.53-2.83)$ & $1.90(0.44-8.11)$ & 0.426 \\
\hline
\end{tabular}

C-peptide concentrations on continuous scale were log-transformed to achieve normality, smaller number of participants because of missing laboratory values of C-peptide

${ }^{a}$ Category cut-points were based on the distribution of controls

${ }^{\mathrm{b}} p$ trend test was based on median values of each category, adjusted for matching factors

${ }^{\mathrm{c}}$ Logistic regression conditioned on matching factors (EPIC recruitment centre, sex, age at recruitment, date at entry in the cohort, time between blood sampling and last consumption of foods and drinks). Adjusting variables in further models: smoking (former smokers adjusted for quitting smoking ( $<10$ or $\geq 10$ years ago), current smokers adjusted for number of cigarettes $(1-9,10-19$ or $\geq 20)$, BMI (continuous))

${ }^{\mathrm{d}}$ Self-reported diabetes at recruitment and $/$ or $\mathrm{HbA}_{1 \mathrm{c}} \geq 6.5 \%(48 \mathrm{mmol} / \mathrm{mol})$

${ }^{\mathrm{e}}$ Non-fasting=last intake $<3 \mathrm{~h}$ ago, in between=last intake $3-6 \mathrm{~h}$ ago, fasting=last intake $\geq 6 \mathrm{~h}$ ago

$p$ interaction by fasting status based on Wald test: crude $p=0.905$, BMI and smoking-adjusted $p=0.806$

risk with $\mathrm{HbA}_{1 \mathrm{c}}$ or C-peptide levels by longer or shorter follow-up times.

With respect to $\mathrm{HbA}_{1 \mathrm{c}}$-a relatively stable and long-term marker for blood glucose levels [19]—our data showed evidence of an association of elevated $\mathrm{HbA}_{1 \mathrm{c}}$ concentrations with increased pancreatic cancer risk independently of diabetes. Indeed, the increase in pancreatic cancer risk was statistically significant from the third category of $\mathrm{HbA}_{1 \mathrm{c}}(5.8-$ $5.9 \%$ [ $40-41 \mathrm{mmol} / \mathrm{mol}]$ ), which does not include diabetic participants $(\geq 6.5 \%$ [ $48 \mathrm{mmol} / \mathrm{mol}])$ or even individuals at the highest risk for progression to diabetes $(\geq 6.0 \%$ [42 mmol/mol] and $<6.5 \%$ [ $48 \mathrm{mmol} / \mathrm{mol}]$ ) based on the definitions of the American Diabetes Association [19]. With few exceptions [20], previous prospective studies have shown statistically significant associations of pre-diagnostic glucose levels with pancreatic cancer risk [12-15]. In these studies, a clear increase in risk was also visible among individuals with intermediate, non-diabetic levels of glycaemia.
Our findings for C-peptide-no significant association with pancreatic cancer risk overall, under fasting or nonfasting conditions - contrast with those from other studies. In a study of four pooled prospective cohorts in the USA, Michaud et al. did observe an increase in pancreatic cancer risk for the highest quartile level of non-fasting plasma Cpeptide, but no association with fasting C-peptide [16]. In the Finnish ATBC cohort, by contrast, pancreatic cancer risk was significantly elevated for the highest quartile of fasting serum insulin [15].

Obesity is an important and frequent determinant of insulin resistance and chronic hyperinsulinaemia [21], and a very strong risk factor for type 2 diabetes [22]. Paradoxically, globally, epidemiological studies have shown only very modest associations of pancreatic cancer risk with BMI or other anthropometric measures of adiposity [4]. Our data showed clear positive correlations of BMI or waist circumference with C-peptide, but very little correlation of 
these adiposity indices with $\mathrm{HbA}_{1 \mathrm{c}}$ (data not shown), in line with findings from other studies [23, 24].

Adiposity-related insulin resistance, while leading to increased plasma insulin levels, may generally not be the only, or even principal, cause of increases in blood glucose levels. Indeed, hyperglycaemia is generally related to a degree of pancreatic beta cell deficiency and insufficient insulin secretion in response to rising glucose levels, and such deficiency is also a central hallmark of all major forms of diabetes. The molecular-pathological pathways leading to the deficiency vary between different forms of diabetes, and it is conceivable that relatively specific forms of pancreatic pathology are at the origin of the hyperglycaemia in individuals who subsequently develop pancreatic cancer. Based on observations indicating that inflammatory pathways play a very central role in the development of pancreatic cancer $[25,26]$ while potentially contributing also to the development of diabetes [27], we speculate that such specific pathology could be a form of chronic and low-grade pancreatic inflammation.

Under the hypothesis that, indeed, a chronic and low-grade form of pancreatic pathology is an original cause of hyperglycaemia in individuals who later develop pancreatic malignancies, we examined whether there are signs of moderate and progressive impairment of the pancreatic beta cell responsiveness, as time intervals till diagnosis of a pancreatic tumour get shorter. Our analyses, however, showed only little heterogeneity of the associations of C-peptide and $\mathrm{HbA}_{1 \mathrm{c}}$ levels with pancreatic cancer risk by length of lag time to cancer diagnosis. Similar lag-time analyses in other prospective studies have led to inconsistent findings so far. In the pooled US cohort [16] and the ATBC cohort [15], there were indications of a stronger association of C-peptide and fasting insulin and glucose levels, respectively, with longer follow-up, whereas two other prospective cohort studies on blood glucose levels and pancreatic cancer risk showed no heterogeneity of these associations by lag time $[12,13]$.

A major strength of our nested case-control study is its prospective design, reducing to a certain extent the possibility of reverse causation, whereas a limitation is the single assessment of biochemical indicators, which may be susceptible to biological variation.

In conclusion, the results of our nested case-control study embedded in a large multi-centre cohort support an association of increasing $\mathrm{HbA}_{1 \mathrm{c}}$ levels with pancreatic cancer risk, independent of BMI or diabetes status. However, in contrast to some previous studies, we did not find an association of elevated C-peptide with pancreatic cancer risk. Overall, combining the results from prospective studies so far, data provide no coherent picture in terms of progressive alterations in glucose and/or insulin metabolism at greater or shorter time intervals prior to pancreatic cancer diagnosis. Further research is needed to understand whether elevated plasma glucose is a possible contributing cause for pancreatic cancer, or whether it is a mere epi-phenomenon pointing towards the existence of a moderate pancreatic disorder that predisposes to the development of pancreatic cancer as well as to diabetes.

Acknowledgements We thank B. Lederer, S. Henke (German Cancer Research Center, Heidelberg, Germany) and P. Matha (Karolinska University Hospital, Stockholm, Sweden) for their excellent work in performing the assays for C-peptide and $\mathrm{HbA}_{1 \mathrm{c}}$ for this study. V.A. Grote was funded by a studentship from the German Research Foundation, Graduiertenkolleg 793 'Epidemiology of communicable and chronic non-communicable diseases and their interrelationships' and this work was, in part, supported by WCRFUK and WCRF International, grant no 2009/39. The coordination of EPIC is financially supported by the European Commission (DGSANCO) and the International Agency for Research on Cancer. The national cohorts are supported by Danish Cancer Society (Denmark); Ligue Contre le Cancer, Institut Gustave Roussy, Mutuelle Générale de l'Éducation Nationale, Institut National de la Santé et de la Recherche Médicale (Inserm) (France); Deutsche Krebshilfe, Deutsches Krebsforschungszentrum and Federal Ministry of Education and Research (Germany); the Hellenic Health Foundation, the Stavros Niarchos Foundation and the Hellenic Ministry of Health and Social Solidarity (Greece); Italian Association for Research on Cancer (AIRC) and National Research Council (Italy); Dutch Ministry of Public Health, Welfare and Sports (VWS), Netherlands Cancer Registry (NKR), LK Research Funds, Dutch Prevention Funds, Dutch ZON (Zorg Onderzoek Nederland), World Cancer Research Fund (WCRF), Statistics Netherlands (the Netherlands); ERC-2009-AdG 232997 and Nordforsk, Nordic Centre of Excellence programme on Food, Nutrition and Health. (Norway); Health Research Fund (FIS), Regional Governments of Andalucía, Asturias, Basque Country, Murcia and Navarra, ISCIII RETIC (RD06/0020) (Spain); Swedish Cancer Society, Swedish Scientific Council and Regional Government of Skåne and Västerbotten (Sweden); Cancer Research UK, Medical Research Council, Stroke Association, British Heart Foundation, Department of Health, Food Standards Agency, and Wellcome Trust (UK).

Duality of interest The authors declare that there is no duality of interest associated with this manuscript.

Contribution statement VAG, SR, AN, HBBM, and RK contributed to the conception and design of this project. VAG analysed and interpreted the data and drafted the first version of this article. SR and RK contributed to the statistical analyses and discussion and reviewed/ edited the manuscript. All authors contributed to the interpretation of data, revised it critically for important intellectual content, and approved the final version for publication.

\section{References}

1. Lynch SM, Vrieling A, Lubin JH et al (2009) Cigarette smoking and pancreatic cancer: a pooled analysis from the pancreatic cancer cohort consortium. Am J Epidemiol 170:403-413

2. Vrieling A, Bueno-de-Mesquita HB, Boshuizen HC et al (2010) Cigarette smoking, environmental tobacco smoke exposure and pancreatic cancer risk in the European Prospective Investigation into Cancer and Nutrition. Int J Cancer 126:2394-2403

3. Raimondi S, Lowenfels AB, Morselli-Labate AM, Maisonneuve P, Pezzilli R (2010) Pancreatic cancer in chronic pancreatitis; 
aetiology, incidence, and early detection. Best Pract Res Clin Gastroenterol 24:349-358

4. Genkinger JM, Spiegelman D, Anderson KE et al (2010) A pooled analysis of 14 cohort studies of anthropometric factors and pancreatic cancer risk. Int J Cancer 129:1708-1717

5. Renehan AG, Tyson M, Egger M, Heller RF, Zwahlen M (2008) Body-mass index and incidence of cancer: a systematic review and meta-analysis of prospective observational studies. Lancet 371:569-578

6. Huxley R, Ansary-Moghaddam A, Berrington de González A, Barzi F, Woodward M (2005) Type II diabetes and pancreatic cancer: a meta-analysis of 36 studies. Br J Cancer 92:2076-2083

7. Pannala R, Basu A, Petersen GM, Chari ST (2009) New-onset diabetes: a potential clue to the early diagnosis of pancreatic cancer. Lancet Oncol 10:88-95

8. Ding XZ, Fehsenfeld DM, Murphy LO, Permert J, Adrian TE (2000) Physiological concentrations of insulin augment pancreatic cancer cell proliferation and glucose utilization by activating MAP kinase, PI3 kinase and enhancing GLUT-1 expression. Pancreas 21:310-320

9. Fisher WE, Boros LG, Schirmer WJ (1996) Insulin promotes pancreatic cancer: evidence for endocrine influence on exocrine pancreatic tumors. J Surg Res 63:310-313

10. Hruban RH, Pitman MB, Klimstra DS (2007) Tumors of the pancreas. Armed Forces Institute of Pathology, Washington, DC

11. Basso D, Plebani M, Fogar P et al (1994) Beta-cell function in pancreatic adenocarcinoma. Pancreas 9:332-335

12. Gapstur SM, Gann PH, Lowe W, Liu K, Colangelo L, Dyer A (2000) Abnormal glucose metabolism and pancreatic cancer mortality. JAMA 283:2552-2558

13. Jee SH, Ohrr H, Sull JW, Yun JE, Ji M, Samet JM (2005) Fasting serum glucose level and cancer risk in Korean men and women. JAMA 293:194-202

14. Johansen D, Stocks T, Jonsson H et al (2010) Metabolic factors and the risk of pancreatic cancer: a prospective analysis of almost 580,000 men and women in the Metabolic Syndrome and Cancer Project. Cancer Epidemiol Biomarkers Prev 19:2307-2317

15. Stolzenberg-Solomon RZ, Graubard BI, Chari S et al (2005) Insulin, glucose, insulin resistance, and pancreatic cancer in male smokers. JAMA 294:2872-2878
16. Michaud DS, Wolpin B, Giovannucci E et al (2007) Prediagnostic plasma C-peptide and pancreatic cancer risk in men and women. Cancer Epidemiol Biomarkers Prev 16:2101-2109

17. Haftenberger M, Lahmann PH, Panico S et al (2002) Overweight, obesity and fat distribution in 50- to 64-year-old participants in the European Prospective Investigation into Cancer and Nutrition (EPIC). Public Health Nutr 5:1147-1162

18. Riboli E, Hunt KJ, Slimani N et al (2002) European Prospective Investigation into Cancer and Nutrition (EPIC): study populations and data collection. Public Health Nutr 5:1113-1124

19. ADA (2009) International Expert Committee report on the role of the A1C assay in the diagnosis of diabetes. Diabetes Care 32:1327-1334

20. Zhou XH, Qiao Q, Zethelius B et al (2010) Diabetes, prediabetes and cancer mortality. Diabetologia 53:1867-1876

21. Kahn SE, Hull RL, Utzschneider KM (2006) Mechanisms linking obesity to insulin resistance and type 2 diabetes. Nature 444:840-846

22. Guh DP, Zhang W, Bansback N, Amarsi Z, Birmingham CL, Anis AH (2009) The incidence of co-morbidities related to obesity and overweight: a systematic review and meta-analysis. BMC Public Health 9:88

23. Meinhold CL, Berrington de Gonzalez A, Albanes D et al (2009) Predictors of fasting serum insulin and glucose and the risk of pancreatic cancer in smokers. Cancer Causes Control 20:681-690

24. Nguyen NT, Nguyen XM, Lane J, Wang P (2011) Relationship between obesity and diabetes in a US adult population: findings from the National Health and Nutrition Examination Survey, 1999-2006. Obes Surg 21:351-355

25. Farrow B, Sugiyama Y, Chen A, Uffort E, Nealon W, Mark Evers B (2004) Inflammatory mechanisms contributing to pancreatic cancer development. Ann Surg 239:763-769, discussion 769-771

26. Lu Z, Li Y, Takwi A et al (2011) miR-301a as an NF-kappaB activator in pancreatic cancer cells. EMBO J 30:57-67

27. Spranger J, Kroke A, Mohlig M et al (2003) Inflammatory cytokines and the risk to develop type 2 diabetes: results of the prospective population-based European Prospective Investigation into Cancer and Nutrition (EPIC)-Potsdam Study. Diabetes $52: 812-817$ 